Pedagogía y Saberes No. 51

Universidad Pedagógica Nacional

Facultad de Educación. 2019. pp. 75-88

\title{
Orientación educativa en Colombia: una línea de trabajo con pretensiones de cientificidad
}

Artículo de reflexión

Educational Orientation in Colombia: A Line of Work with Scientific Pretensions

Orientação educacional na Colômbia: uma linha de trabalho com pretensões de cientificidade

Faustino Peña Rodríguez*

\section{Para citar este artículo:}

Peña, F. (2019). Orientación educativa en Colombia: una línea de trabajo con pretensiones de cientificidad. Pedagogía y Saberes, 51, 75-87.

Doctor en Educación. Profesor asociado de la Facultad de Educación de la Universidad Pedagógica Nacional, programa de Psicología y Pedagogía. Miembro del grupo de investigación Equidad y diversidad en educación.

Correo electrónico: fprodriguez@pedagogica.edu.co

Código ORCID: orcid.org/0000-0002-2358-4462 


\title{
Resumen
}

La orientación educativa no se consolidó en Colombia como línea de trabajo educativo porque intentó hacerlo ligada a aspectos científicos, sin tener la fundamentación teórica y práctica para llevarlo a cabo y sin que esa hubiera sido la idea fundacional. Este artículo de reflexión propone que la orientación educativa es una línea de trabajo o acción que deriva sus saberes de campos como la psicología, la educación, la psicopedagogía y la sociología; áreas que, históricamente, han tenido grandes dificultades para consolidarse, con excepción de la sociología. El artículo se centra en argumentar, en primer lugar, que educar es un concepto más abarcador que orientar y no sería necesario hacer referencia a la acción de orientar, cuando existe la de educar. En segundo lugar, que la constitución de algunos de los campos que han provisto a través de la historia los saberes y conocimientos a la orientación educativa, muestra las indefiniciones teóricas tanto de los primeros como de la última y, sobretodo, que las pretensiones de cientificidad de la orientación han hecho más mal, que bien.

\section{Palabras clave}

orientación educativa; psicología individual; psicopedagogía; educación; pedagogía

\begin{abstract}
The educational orientation was not consolidated in Colombia as an educational work line because it tried to do it linked to scientific aspects, without having the theoretical and practical foundation to carry it out and without it being the foundational idea. This reflection article proposes that educational guidance is a line of work or action that derives its knowledge from fields such as psychology, education, psychopedagogy and sociology; areas that, historically, have had great difficulties to consolidate, with the exception of sociology. The article focuses on arguing in the first place, that education is a more comprehensive concept than guiding and it would not be necessary to refer to the action of guiding, when educating exists. Second, that the constitution of some of the fields that have provided, through history, knowledge to educational orientation, shows the theoretical vagueness of both the former and the latter and, above all, that the pretensions of scientific orientation have done more harm than good.
\end{abstract}

\section{Keywords}

educational orientation; individual psychology; psychopedagogy; education; pedagogy

\section{Resumo}

A orientação educacional não se consolidou na Colômbia como uma linha de trabalho educacional, porque tentou fazê-lo vinculada a aspectos científicos, sem ter a fundamentação teórica e prática para realizá-lo e sem o que teria sido a ideia fundacional. Este artigo de reflexão propõe que a orientação educacional é uma linha de trabalho ou ação que deriva seu conhecimento de campos como a psicologia, a educação, a psicopedagogia e a sociologia; áreas que, historicamente, tiveram grandes dificuldades para se consolidar, com exceção da sociologia. 0 artigo centra-se em argumentar, em primeiro lugar, que a educação é um conceito mais abrangente o que orientar e não seria necessário referir-se à ação de orientar, quando existe a de educar. Em segundo lugar, que a constituição de alguns dos campos que forneceram ao longo da história os saberes e conhecimentos à orientação educacional, mostra a imprecisão teórica tanto do primeiro quanto do último e, acima de tudo, que as pretensões de orientação científica fizeram mais mal do que bem.

\section{Palavras-chave}

orientação educacional; psicologia individual; psicopedagogia; educação; pedagogia 


\section{Cientificidad(es)}

Toulmin (citado por Peña, 2006) expresa que las empresas racionales pueden tomar dos fases: la de las disciplinas, las cuales desarrollan tradiciones frente a procedimientos y técnicas con el fin de abordar problemas teóricos y prácticos, y en este sentido, los resultados son temas para la historia de las ideas en cuanto paradigmas, teorías, enfoques o corrientes construidos por los y las militantes en las mismas; o la de las profesiones, organizadas a través de instituciones, roles y personas que buscan mejorar esos procedimientos y técnicas. Las disciplinas tienen características que las constituyen como tal, se puede hacer su reconstrucción histórica y epistemológica (cómo surgió, a qué problemas buscó dar respuesta, relaciones con la sociedad del momento, cambios temporales en torno a los problemas a los que dio respuesta y en la forma de hacerlo, conceptos propios, en síntesis, recuperación de sus tradiciones porque son estas las que posibilitan la producción de conocimiento); existencia de comunidades académicas que las desarrollan y promueven; y, se despliegan lenguajes, lógicas y códigos específicos en torno a particulares objetos de saber y campos de problemas.

Para Bernstein (1990) lo que opera en las prácticas pedagógicas de formación profesional es una recontextualización del discurso disciplinado, cuya base está permeada por un lenguaje multidisciplinario. En esta perspectiva, las profesiones no existen bajo la forma de disciplinas sino bajo la forma de prácticas con soporte multidimensional del conocimiento e incluso como yuxtaposición de disciplinas.

El discurso de la profesión involucra muchas disciplinas, lenguajes, discursos, saberes, experiencias, teorías y paradigmas que las constituyen como tal. La profesión está respaldada, en principio, por el título y por unas características que definen sus condiciones fundamentales, título y características que profieren legitimidad social: 1) un cuerpo especializado y patrones comunes de intervención práctica; 2) un importante componente ético, la deontología profesional, que se dirige a satisfacer las necesidades de los clientes; 3) una fuerte identidad personal, sentido de pertenencia a dicho ámbito ocupacional y, 4) un control colegial sobre la selección, habilitación, evaluación y permanencia de sus componentes (Pérez, 1998).

El primer aspecto remite a la comunidad profesional, la cual define los desempeños que le son propios; el segundo, hace referencia a las formas colectivas de actuar y proceder; el tercero, conlleva la construcción de aspectos identitarios de parte de los profesionales del campo respectivo y el apego de sus integrantes a estos; por último, control, de los aspectos prácticos y teóricos que entran al campo profesional y de sus inte- grantes, esto es, del acceso y permanencia. Así, el ejercicio profesional es realizado desde un lugar y ese lugar es controlado por sus miembros, ello sin olvidar que:

La crisis de los universales clásicos afecta a todos los aspectos de lo social: crisis de la representación, crisis histórica (de legitimación universal de los grupos dominantes), crisis ética (de la función de la ley), crisis política (de los ideales), crisis artística (de las formas), etc. (Badiou, citado por Frigerio y Diker, 2008, p. 7).

El manejo dado a los espacios define quiénes somos y qué valoramos; de acuerdo con Augé (2000), el lugar puede estar ligado a un espacio donde confluyen personas y perspectivas, pero también, se puede ubicar como espacio fundamental de las relaciones humanas y por ello cruce de caminos, lo cual evoca el concepto de campo.

La discusión desde las profesiones conlleva elementos importantes sobre la forma como estas se conforman y desarrollan a partir de aspectos clave, como se ha mostrado con anterioridad. Tomar el camino de los campos como lo hace Bourdieu (1975) puede ampliar la perspectiva. Desde el sociólogo francés, un campo se estructura al definir lo que está en juego, los intereses específicos, la percepción de las reglas del campo, las disposiciones de los individuos para entrar en ese campo, en tanto estén dotados de los habitus para conocer y reconocer las leyes inmanentes al juego y gente dispuesta a jugar (Bourdieu, 1990). La noción de campo remite al lugar creado con la finalidad de diferenciar y diferenciarse, reconocer y desconocer, pero al mismo tiempo por el que los que participan en él son determinados. Así, lo que se constituye es un campo de fuerzas, un campo de luchas en donde autonomía-dependencia son partes de esa relación creadora, pero al igual diferenciadora, lo que comporta que se conozcan las condiciones históricas y sociales en las cuales el campo se constituye y que hacen posible su existencia, además, de adquirir significado (Peña, 2013). En esta perspectiva, es posible ubicar la discusión que plantean Zuluaga y Echeverri (2003) quienes propusieron el concepto de campo pedagógico, el cual tiene su base en el horizonte conceptual de la pedagogía, y por ello ligado al saber y a su recorrido histórico, así, los conceptos articuladores son enseñanza, formación, instrucción, aprendizaje y educación los cuales dan cuenta de su fortaleza epistemológica y de los elementos mediante los cuales - y a partir - dialoga y le da autonomía. Para ellos, el problema no es que el campo pedagógico esté atravesado por múltiples paradigmas "[...] lo esencial es la traductibilidad de los conceptos y las experiencias que las distintas tendencias producen" 
(Zuluaga y Echeverri, 2003, p. 119). Al ser campos bien sea pedagógico, psicológico o de la orientación educativa-deben presentar en escena (colocar al servicio de las comunidades académicas) sus conceptos articuladores, saberes, recorrido histórico y la forma como estos conllevan diálogos y autonomías.

El conflicto dirigido a indagar cuándo se está frente a una disciplina, ciencia, campo de saber o campo pasa por la época y cambio de concepciones. En la actualidad, muchos campos han abandonado las pretensiones científicas no solo por no cumplir ni poder cumplir con tener un objeto y método definido sino porque se constituyeron bajo otros parámetros que no los hacen menos ni más, sino diferentes (campo de la infancia, campo tecnológico, campo de la sociología jurídica). Lo fundamental frente a este conjunto o indagación es analizar: 1) el lugar que ocupa en el seno de la sociedad mediada por su lugar en las instituciones, aspecto que confiere un campo de saber especial (Zambrano, 2007); 2) investigaciones y fenómenos que estudia lo cual le confiere un estatus particular (Zambrano, 2007); investigaciones y saberes desde el plano de sus especificidades y constitución, esto es, no se trata de cantidad y generalidad sino del campo autónomo construido que abarca su actuación y acción, que constituye rituales - socializaciones, publicaciones, eventos-, prácticas y experiencias situadas, esto es, a qué problemas busca responder y los referentes teóricos y metodológicos desde donde lo hace; 3) lugar que ocupa en el seno de la sociedad y de las comunidades académicas, aquí, el aspecto institucional se amplía a la sociedad y a las comunidades académicas en general y, 4) saberes y autores paradigmáticos. Así las cosas, en el espacio social, el lugar se gana producto de estos aspectos en conjunto.

\section{Constitución de la psicología, la psicopedagogía y la orientación educativa}

En la perspectiva de campo, hay tres conjuntos que han luchado por posicionarse y que denotan, en muchos aspectos, un solo campo que se complementa, esto es, la psicología, la psicopedagogía y la orientación educativa. Miremos estos campos en su constitución y complejidad.

\section{Aspectos ligados al desarrollo de la psicología}

En perspectiva epistemológica, preguntarse por una disciplina, ciencia o campo de saber es hacerlo por su sentido, hacia dónde dirige su acción teórica y práctica y con qué fundamentos, estas preguntas la definen como tal y le dan lo que de modo genérico se llama su identidad y su esencia. Canguilhem (1998) señala:

[...] para la psicología la pregunta por su esencia, o más modestamente, por su concepto, pone también en tela de juicio la existencia misma del psicólogo, en la medida en que no pudiendo contestar exactamente lo que él es, le queda muy difícil dar una respuesta sobre lo que hace. Él no puede entonces buscar sino en una eficacia, siempre discutible, la justificación de su importancia como especialista, importancia que a algunos no les desagradaría, en modo alguno, y que en el filósofo engendraría un complejo de inferioridad. (p. 7).

Bajo estos parámetros "la psicología aspira pues a construir un saber científicamente producido, saber acerca de algo genéricamente designado como psiquismo y en general considerado como un fragmento esencial de lo humano" (Pérez, 1992, p. 55), esto es, como especialista.

A lo largo de la historia, se evidencia que la psicología no está constituida como los cánones epistemológicos tradicionales lo indican, ya que es gracias a otras disciplinas que ha cimentado su quehacer y razón de ser para abarcar ámbitos, como el clínico, salud, educación, comunitario y social, forense, recursos humanos, investigación y orientación educativa. Los cambios que la psicología ha tenido en cuanto a su definición se refieren, por consecuencia, a su objeto de estudio y metodología. Desde varios referentes se ha señalado que nadie ha conseguido definir qué es la psicología y que, lo que ha hecho, es dar muchas respuestas que han llevado a los sujetos y colectivos a formularle muchas preguntas. El espíritu humano, la psique, el alma, el inconsciente o la personalidad, entre otras cosas, la constituyen y es aquí donde la psicología puede ser el cúmulo de muchas opciones y a la vez ser cualquier cosa - cuestión que también puede estar sucediéndole a la psicopedagogía y a la orientación educativa-.

Apoyándose en la indefinición, se justifica a la psicología por sus logros técnicos o por la manera en que contribuye a crear imágenes del hombre, a orientar la opinión pública, a gobernar la conducta de las masas, etc. (Braunstein, 1982). Los procesos psíquicos o mentales (pensamiento, lenguaje, memoria, imaginación, percepción, sentimientos) son objeto de estudio no solo de la psicología, sino de otras ciencias como la fisiología, la teoría del conocimiento o la lógica (Montealegre, 1994). Braunstein (1982) propuso reorientar el estudio de la psicología y concebirla más bien como una herramienta metodológica y aquella teoría adecuada para tratar con la subjetividad humana. En su concepto, si la psicología se ocupa de la concien- 
cia y la conducta, no es una disciplina científica; tal reorientación conllevaría, a su vez, modificar líneas de trabajo como la orientación educativa.

\section{Aspectos ligados al desarrollo de la psicopedagogía}

Zambrano (2007) cuestiona si la psicopedagogía es ciencia, saber o discurso y realiza sus reflexiones desde el horizonte de las Ciencias de la Educación en Francia; señala que en Francia la psicopedagogía en sus inicios estuvo conformada por la psicología y la filosofía. Corre el año de 1883 y en las universidades se dictan unos cursos de ciencias de la educación que no estaban asociados por un interés relevante del Ministerio de instrucción pública ni por los profesores que los dictaban. En su relato, entre 1884 y 1903 se abren cursos de ciencias de la educación dirigidos a profesores de educación primaria con currículo libre y no conducentes a título alguno, con predominancia de la psicología que había alcanzado para entonces un sitial importante en el campo científico (la medición de la inteligencia se imponía sobre los saberes escolares):

[...] los aportes de Piaget, Wallon y de los trabajos que impulsaron algunos especialistas como Mialaret, Vial, Debesse, Fraise, Oleron, Chatêau , así como la lectura tardía de la obra de Vygotsky se constituirán, desde la primera mitad del siglo xx, en el factor teórico y el horizonte de trabajo de la psicopedagogía. (Zambrano, 2007, p. 121).

Finalmente, es claro al indicar que el campo de estudio de la psicopedagogía no encontró asidero en Francia en cuanto no logró constituir un objeto y unas bases científicas.

Varios autores (Peña y Acevedo, 2011; Zambrano, 2007) han señalado que la complejidad de la constitución de la psicopedagogía tiene que ver con el hecho de haber querido crear una ciencia que abordara el hecho educativo en su conjunto, idea que se arraiga en las ciencias de la educación pero que resulta imposible para una sola de ellas, por lo que el trabajo interdisciplinario se vuelve fundamental, en tanto solo juntas pueden explicar los procesos y procedimientos para la formación, bien sea bajo la égida de individuo, sujeto, estudiante o alumno. En este sentido, es fundamental establecer qué aporta cada uno de los conjuntos disciplinares que constituyen el conjunto.

Carvajal (2005) muestra que existe la concepción de los propios psicopedagogos en el sentido que la psicopedagogía estudia al sujeto en situación de aprendizaje. Sin embargo, cuestiona que ese objeto no es diferente del de la psicología. Para él, psicopedagogía es
[...] una palabra contracta que aglutina en su forma otras dos palabras: psicología y pedagogía; pero psicología y pedagogía ya son ellas mismas contractas, cada una, respectivamente, aglutina otras dos: $p s i$ que y logos (psicología); paidos y ago (pedagogía). Esto significa que la palabra psicopedagogía es una palabra compuesta de otras cuatro, todas de origen griego, que equivalen, en últimas a el alma (psique), el decir (logos), el niño (paidos), la conducción (ago). (Carvajal, 2005, p. 1).

El estudio de Moreu y Bisquerra (2002) expresa que los orígenes de la psicopedagogía se remontan a los desarrollos que en el siglo xix logró la psicología, catalogados como una nueva psicología por lo que fue nombrada como científica, producto de interactuar y fortalecer el biologismo y el positivismo, aspecto que no desarrolló la llamada psicología tradicional. La nueva psicología es implementada por médicos fisiólogos "...poniendo en práctica nuevas técnicas de experimentación psicofisiológica y psicométrica, y renegando de las ancestrales concepciones filosóficas que hasta entonces habían constituido el corpus de la psicología" (Moreu y Bisquerra, 2002, p. 18). Esta psicología experimental es vista como una necesidad en la escuela y la educación, ligada a su carácter científico y a nuevas preocupaciones sociales como el estudio de la infancia y la generalización de la educación a sectores excluidos hasta entonces.

Las escuelas se abrieron, así, a médicos fisiólogos con la finalidad de tratar problemáticas como la edad mental o el tratamiento de niños desamparados, con deficiencias físicas, sensoriales o psíquicas, en fin, para tratar la salud mental. La normalidad y anormalidad toman fuerza dentro de la escuela, sus diferentes discursos son los vestigios de lo que más adelante se conocerá como psicopedagogía (síntesis de psicología, pedagogía y medicina). El surgimiento de la psicopedagogía está ligado al intento de finales del siglo XIX y comienzos del xx, de tomar los desarrollos de la nueva psicología para fundar una pedagogía científica (Moreu y Bisquerra, 2002).

La historia coincide en que es en 1908 cuando se encuentran los primeros vestigios de la aparición del término psicopedagogía en países como Francia, Italia, España, Suiza y Bélgica y que es la educación de los deficientes su objeto inicial; la psicopedagogía intentará definir un campo de actuación que involucre a maestros y médicos o a maestros y psicólogos en este propósito. Así, se crearon metodologías psicopedagógicas que fueron utilizadas en actividades como la salud mental, corrección y protección de menores, orientación escolar y profesional, fonética experimental, psicoanálisis aplicado a la educación, psicopatologías escolares, todas dirigidas a las escuelas 
que se suman a la de educación especial, en donde se usó en un principio. Es necesario reiterar que, en sus inicios, la psicopedagogía es conocida como una técnica o metodología que deriva sus conocimientos de la medicina, psicología y pedagogía; en esta perspectiva, se diseñan cursos dirigidos, en particular, a maestros en ejercicio y a profesionales interesados en las deficiencias mentales.

A partir de lo anterior, puede decirse que la psicopedagogía en Europa no tuvo pretensiones de consolidarse como una ciencia o disciplina, o fracasó en su intento y lo que se conoce como psicopedagogía son técnicas o metodologías derivadas de sus saberes fundantes:

\section{[...] en los años cincuenta y sesenta se crean en las universidades laboratorios o cátedras de psicopeda- gogía. No obstante, en esos mismos años, se alzan voces de filósofos que declaran que, en realidad, ese término de psicopedagogía está mal constituido y mal fundamentado; que la reflexión sobre los fines y los principios de la educación no puede basarse en los resultados de una psicología, por científica que sea; que la psicología no puede ser ni una norma para la acción de los maestros, ni una explicación suficiente de los fenómenos educativos. (Best, 1988, p. 11).}

La segunda posguerra posibilitó la consolidación de diferentes formas de la psicopedagogía, en especial en América Latina - corriendo en paralelo con la orientación, especialmente la vocacional y profesional-. En Argentina, Uruguay y Chile las carreras de psicopedagogía tienen un fuerte componente psicológico y, por ende, están inscritas en facultades de Psicología, Psicología y Ciencias pedagógicas, Desarrollo, Humanidades y Ciencias humanas, entre otras. Estas carreras preparan para atender procesos psicopedagógicos ligados a la enseñanza y el aprendizaje:

El Licenciado en Psicopedagogía de la UCA puede participar en equipos interdisciplinarios responsables de la elaboración, ejecución y evaluación de planes, programas y proyectos de las áreas de educación, salud y trabajo. Realizar estudios e investigaciones referidos al quehacer educacional, de la salud y del trabajo en relación con el proceso de aprendizaje y a los métodos, técnicas y recursos propios de la investigación psicopedagógica. También está capacitado para realizar diagnósticos de los aspectos perturbados de una persona que comprometan su proceso de aprendizaje, y efectuar pronósticos de evolución, implementar estrategias específicas de rehabilitación, orientación y derivación destinados a promover procesos armónicos de aprendizaje. (Programa de la Universidad Católica de Argentina).
En este camino, no preparan para desempeñarse en las ciencias de la educación o en la pedagogía. En el primer caso, no profundizan en psicología, sociología, filosofía o economía de la educación; en el segundo, aspectos como la formación de maestros, el desarrollo de currículos y la evaluación, entre otros, están focalizados hacia el aprendizaje y sus anomalías, esto es, el aprendizaje individual y sus dificultades direcciona el trabajo de formación. Así lo confirma el perfil del egresado del programa de Licenciatura en psicopedagogía de la Universidad Nacional General San Martín de Buenos Aires: asistir al sujeto en situación de aprendizaje desde un abordaje individual, grupal y comunitario; asesorar a los distintos actores involucrados en el proceso de aprendizaje con el fin de prevenir perturbaciones, con especial atención en los estadios psicoevolutivos; darse cuenta respecto a anomalías de aprendizaje y proponer y aplicar estrategias para su mejoramiento; desarrollar materiales educativos dirigidos a niños con necesidades educativas especiales; y desarrollar estrategias de intervención entre otras.

En países como Venezuela, Colombia y España la psicopedagogía está inscrita en Facultades de Educación y sus planes de estudio hacen referencia a procesos educativos en general. Tanto en unos como en otros países, la orientación educativa está planteada en el perfil profesional del egresado, como una actividad para desarrollar bien sea que se trate de la psicopedagogía, las ciencias de la educación, la psicología o la pedagogía.

En Colombia se forman psicopedagogos desde la segunda mitad del siglo Xx. Aspectos ligados al aprendizaje, comportamiento, deserción y repitencia en el nivel de básica primaria estuvieron en sus propósitos iniciales. En las décadas de los años 60 y 70 se ligó a la primera tecnología educativa en tanto estaba en auge el desarrollo económico y el papel de la educación para lograrlo, por lo que se vuelven necesarias actividades como diseño, planeación, organización, dirección y coordinación de las actividades de las instituciones educativas (Peña y Acevedo, 2011). Desde esta formación, se establecen acciones hacia la orientación de la vocacionalidad, elección de carrera y direccionamiento del desempeño profesional (Peña y Acevedo, 2011), perspectiva que fue acompañada de modo particular por la Universidad Pedagógica Nacional, y coadyuvó en la fundación de los Institutos Nacionales de Educación Media Diversificada-INEM- con la finalidad de articular los diferentes niveles escolares en torno a la vocacionalidad, elección de carrera y profesionalismo.

La psicopedagogía en sus intencionalidades quiso trabajar teniendo como soporte la psicología, pedagogía y, en general, los aportes de las ciencias de la 
educación para lo cual la orientación era uno de sus componentes. Sin embargo, por un lado, la orientación educativa no apareció clara en los planes de estudio de las mencionadas carreras; y de otro, en tanto acción que tenía que ver con varias carreras de las ciencias sociales y humanas, la orientación siempre quiso hacer causa aparte, así, se constituyó como gremio y se hizo nombrar de forma particular, de tal manera, que no se trató del psicólogo, psicopedagogo, sociólogo, trabajador social, fonoaudiólogo, terapeuta ocupacional, terapeuta del lenguaje... sino del Orientador; en este camino, realizó unas luchas políticas - de reconocimiento como grupo- antes que de identidad y sentido.

\section{Aspectos ligados al desarrollo de la orientación educativa}

Es evidente que la acción orientadora está inmersa en general en campos específicos como el psicopedagógico y el psicológico, y que de allí deriva su acción, pero ¿qué sucede cuando orientar tiene sus propias complicaciones?:

[L]a orientación se reduce prácticamente al diagnóstico de las habilidades de un sujeto para la predicción del éxito o el fracaso futuros. Ello supone la creencia de que existe un isomorfismo entre capacidades y desempeño profesional y/o académico. Esta linealidad es poco admisible si tenemos presente los rápidos cambios tecnológicos que propician constantemente modificaciones sustanciales del mundo ocupacional. (Morril, Oetting y Hurst, 1974, p. 24).

En la actualidad, no se presenta el mencionado isomorfismo, sin embargo, la orientación no ha producido perspectivas que la saquen de dicha creencia; hay desarrollos en torno a las capacidades, desempeños profesionales y académicos, pero no por cuenta de la orientación educativa.

La orientación surgió como orientación vocacional dirigida a la profesionalización —analizar lo vocacional con miras a formar los profesionales que la sociedad requería, para satisfacer así necesidades tanto individuales como colectivas-. Su conceptualización se fue ampliando a partir de aportes sociológicos dirigidos a la revolución de la carrera en los años cincuenta del siglo $\mathrm{xx}$, y adoptó de forma progresiva un enfoque del ciclo vital. Aportaciones posteriores, como la educación para la carrera en los años setenta, han propuesto la integración curricular y el desarrollo de la carrera en las organizaciones, entre otras propuestas, produciendo una cruzada dirigida a la orientación profesional - ya no solo vocacional-.

En los países europeos se pensó de modo formal la orientación desde finales del siglo XIX, cuando Bélgica fundó su primer instituto de psicología y pedagogía, sin embargo, fue en la primera mitad del siglo xx que esta se fortaleció, por ejemplo, con la creación del Museo Social (1909) o el Secretariat d'Aprenentatge (1914) de Barcelona. El principal propósito de la orientación era la felicidad de los individuos y la máxima armonía resultante en toda la nación (Bisquerra, 1996). Frank Parsons imaginó una sociedad donde la cooperación reemplazara la competencia, su propósito fue:

ayudar a los jóvenes a elegir una ocupación, prepararse para ella, encontrar una apertura en ella, y construir una carrera de eficiencia y éxito. Para ayudar a cualquiera, joven y adulto, que buscara consejos en cuanto a oportunidades y recursos para el mejoramiento de su condición y los medios para aumentar su economía eficazmente. (Parsons, 1909).

En un principio, la orientación se concibió como algo aislado y extraescolar, pero con el transcurrir del tiempo, se abrió espacio en la escuela, ya que la sociedad exigió que al ser esta la primera trabajadora del conocimiento, acogiera la orientación y se cambiara el papel predominante de la escuela como transmisora de valores e intercambio de informaciones y experiencias, para verse como aquella capaz de aportar una guía para el autoconocimiento y el desarrollo de habilidades propias de cada uno de sus estudiantes. Con esto se permitía a cada individuo materializar sus mejores herramientas de adaptación en su comunidad, al propiciar un desarrollo a nivel socioeconómico, entrelazando las destrezas, gustos de cada sujeto, y los intereses y necesidades de la sociedad a la que perteneciera (Subirana, 2013).

En esencia, se señaló la dependencia que la orientación debía tener según el desarrollo tanto social como económico de cada Estado y la estrecha relación entre el sector productivo y el sistema educativo. Pese a las similitudes culturales y modelos teóricos, cada país estableció los objetivos de su sistema educativo y, en concreto, en el ámbito de orientación educativa. De igual forma, la orientación se vio como una manera de transformar de modo radical las propuestas formativas y los objetivos tradicionales en los que se habían fundamentado hasta el momento y desenvuelto dichos sistemas educativos (Subirana, 2013). Se crearon proyectos, programas y redes educativas que dieran solución a los periodos de mayor tensión e incertidumbre de cada estudiante, desde el campo de la institucionalidad; no solo para atender un carácter escolar y profesional, sino el mismo periodo de transición a la vida adulta y laboral. Se dio así, un lugar de mayor importancia a la orientación como aquel proceso educativo capaz de conseguir una educación integral, que permitiera a cada estudiante entrelazar su perfil con su propio entorno. 
En Estados Unidos la orientación se origina en la primera década del siglo Xx. En sus inicios la preocupación se centró en el análisis y diagnóstico de las capacidades de las personas ante la elección vocacional, con base en las ideas de Frank Parsons - considerado el padre de la orientación profesional desde su faceta de reformador social y desde el Breadwinner's Institute y el Vocation Bureau, que tenían como objetivo el desarrollo de programas educativos para inmigrantes y jóvenes que buscan empleo-y su obra Choosing a Vocation (1909). A partir de los años 50 del siglo XX, en los Estados Unidos, la orientación comenzó a introducirse en los contextos escolares debido a que un profesor no podía, con las horas de docencia de las que disponía, atender todas y cada una de las necesidades que surgían en su alumnado (Ruiz, 2010).

En este país, la orientación vocacional y profesional se centró en la promoción del autoconocimiento por parte del alumno y la capacitación e inserción profesional de los jóvenes de las clases más desfavorecidas, lo cual beneficiaría el trabajo participativo y activo de estos jóvenes dentro de la sociedad, situación igual a la ocurrida en Europa.

Europa y los nuevos estados americanos llevaron a cabo tres modelos de orientación profesional desde la Educación superior:

- El alemán, también llamado humboldtiano, se organizó mediante instituciones públicas, con profesores funcionarios y con el conocimiento científico como meta de la universidad. En ella, el objetivo era formar personas con amplios conocimientos, no necesariamente relacionadas con las demandas de la sociedad o del mercado laboral. La idea que sustentaba el modelo (heredada del idealismo alemán del siglo XVIII) era que una sociedad con personas formadas científicamente sería capaz de hacer avanzar al conjunto de la sociedad en sus facetas sociales, culturales y económicas. De hecho, fue así durante más de un siglo, y las universidades alemanas ayudaron no poco a convertir al país en una potencia científica y económica.

- El modelo francés, también llamado napoleónico, tuvo por objetivo formar a los profesionales que necesitaba el Estado-nación burocrático recién organizado por la Francia napoleónica. Las universidades se convirtieron en parte de la administración del Estado para formar a los profesionales que ese mismo Estado necesitaba. Los profesores se harían funcionarios públicos, y las instituciones estarían al servicio del Estado más que al de la sociedad. El modelo, exportado a otros países del sur de Europa, tuvo éxito también para la consolidación de las estructuras del Estado liberal.

- El modelo anglosajón, al contrario de los dos anteriores, no convirtió en estatales a las universidades, manteniendo el estatuto de instituciones privadas que todas las universidades europeas tenían hasta principios del siglo XIX. En las universidades británicas, cuyo modelo se extendió a las norteamericanas, el objetivo central fue la formación de los individuos, con la hipótesis de que personas bien formadas en un sentido amplio serían capaces de servir adecuadamente las necesidades de las nuevas empresas o las del propio Estado. Este modelo, como los otros, también tuvo éxito en los países en los que se aplicó, pero, a diferencia de los otros, resistió mejor el paso del tiempo y parece estar más adaptado al contexto actual. (Mora, 2004, pp. 2-3).

Se destaca así, la inscripción de la orientación profesional como modelo - en singular, en cuanto en los países referenciados se aplicó uno de ellos-, realizado desde la Educación superior e inscrito dentro de saberes y conocimientos existentes.

Por su parte, la orientación psicopedagógica se creó sobre la base de que en la intervención de la orientación educativa participan muchas disciplinas o saberes. Álvarez y Bisquerra (1996) recién han señalado que todavía es escasa la literatura sobre modelos de orientación y sus tipos, no obstante, diversos autores han realizado propuestas de clasificación de los modelos de intervención en orientación. En la actualidad, existe una gran variedad de estos modelos: clínico, de consulta, de servicios, programas, tecnológico, psicopedagógico, etc. Así, se plantearon y construyeron modelos, para desarrollar la idea fundacional de la orientación, no para constituirse como ciencia o profesión.

Cabrera y Platone (2005) afirman que es necesario:

[...] considerar la urgente necesidad de replantearse las nociones de orientación vocacional de acuerdo a concepciones teóricas actualizadas que no simplifiquen el problema en términos de excelencia para la inserción al mercado de trabajo, sino que tomen en cuenta la mayoría de las dimensiones personales y sociales que tendrían más que ver con la pertinencia de la formación educativa y personal del estudiante, brindándole la oportunidad de ser un sujeto activo, creativo, consciente y comprometido en su toma de decisiones. (p. 467). 
La orientación educativa en Colombia surge normativamente en 1954, cuando se advierte el fracaso de los estudiantes en la escogencia de sus carreras, y se fundan seis institutos de estudios psicológicos y de orientación profesional. Mosquera (2013) expone que la orientación educativa aparece como un intento de disciplina y profesión al ver que los bachilleres no sabían cómo exteriorizar y materializar sus propias inclinaciones vocacionales, lo que esperaban para su futuro, sus planes y propósitos, sus ambiciones y motivaciones, por lo que se hacía pertinente una línea de trabajo que tuviera inmersión en la orientación profesional y educativa aplicada a nuestro contexto.

En Colombia, dados los problemas y las necesidades que enfrentaba el país, se intentó dar a la orientación su propósito y razón de ser desde el estudio, análisis, propuestas y ayudas para el desarrollo psicológico del estudiante y que este tuviera una adaptación tanto en la escuela como en la vida cotidiana; que en el trascurso de su época escolar lograra acogerse con mayor facilidad a los cambios de ambiente y así alcanzar su máximo potencial de desarrollo. Pese a la integración de la orientación profesional desde diferentes perspectivas, no logró el fortalecimiento de la calidad de la práctica profesional en los diferentes contextos laborales (Mosquera, 2013).

La orientación en Colombia, a diferencia de otros países en los que está inscrita en el perfil de carreras como ciencias de la educación o pedagogía, aparece asociada sobre todo a la psicopedagogía y a la psicología. De una u otra forma, hace parte consubstancial de la educación y de ninguna manera, algo aparte; su origen está asociado a la educación de la vocacionalidad que por diferentes motivos será llamada elección vocacional:

La expansión industrial y posindustrial, por ejemplo, promueve el desenvolvimiento de esta práctica fomentadora de la elección individual; las comunidades preindustriales, con su escasa división de la mano de obra y su tradición de roles prescriptos suelen permitirse la ausencia del servicio. Los regímenes democráticos, a la vez, y no los totalitarios, conforman el humus donde la orientación vocacional germina y se expande. En ellos también es concebible un tipo de movilidad social que no solo obedece a factores estructurales sino a valoraciones y creencias, como las que presentan a los actores sociales construyendo su propio destino. (Di Doménico y Vilanova, 2000, p. 48).

\section{Discusiones necesarias}

¿Educar u orientar?: la orientación educativa se nombra bajo acciones que, analizadas por separado de la acción educativa y de la acción pedagógica, tienen asidero y no tendrían mayor objeción. Sin embargo, al entrar en profundidad en lo que significa educar y el quehacer pedagógico - independiente de las concepciones con que se les mire- se encuentra a la orientación y sus pretensiones como desenfocadas, en tanto, orientar es parte fundamental de la formación y no el todo, como ha querido aparecer, por lo menos, en el contexto colombiano.

En perspectiva epistemológica se puede preguntar por los paradigmas, teorías, enfoques o corrientes construidos por la orientación educativa con el fin de abordar problemas teóricos y prácticos, esto es, los elementos aportados que posibiliten hacer su reconstrucción histórica y epistemológica. Como profesión, preguntar por las instituciones que otorgan títulos y por los desempeños propios, formas colectivas de actuar y proceder, aspectos estos que dan identidad a los profesionales y formas de ejercer control del campo, para corroborar que no cumple con ninguno de estos requisitos.

La orientación educativa no es una profesión, en tanto en Colombia no existe titulación de orientadores ${ }^{1}$ - en el mundo tampoco ${ }^{2}$ - En Colombia, los llamados Orientadores en los colegios de básica primaria, secundaria y media provienen de campos de saber que en su mayoría no abordan su problemática; en el caso de los profesionales que desempeñan esta función en la escuela, Hernández (2018) establece que su formación es psicología (46.1\%), licenciatura en psicopedagogía (27.7\%), trabajo social $(15.3 \%)$ y otra -fonoaudiología, terapia del lenguaje, sociología- $(10.9 \%)$, tampoco son posgraduados en Orientación.

Estos aspectos conducen a diferenciar entre orientación y psicopedagogía. Para Abisambra y Jiménez (1973) la orientación se relaciona con asesoramiento, consejería, consultoría; varía según el objetivo (escolar, vocacional, profesional, personal, matrimonial, familiar, rehabilitatoria, terapéutica) y los campos de desempeño del orientador son instituciones educativas, instituciones dedicadas al entrenamiento de personal calificado, esto es, la industria. Por otra parte, señalan que la psicopedagogía es la ciencia a la que le corresponde la dirección del proceso de enseñanzaaprendizaje y la adecuación de los factores que en él intervienen.

1 Hubo algunos casos, pero nunca sistemáticamente.

2 También, hay algunos casos. 
Los objetivos del desempeño del orientador estarán ligados a contribuir al funcionamiento del servicio de orientación en las instituciones educativas, fomentar el estudio sistemático del comportamiento de los alumnos de la institución, ayudar al estudiante en el análisis de su rendimiento académico, promover una selección, una clasificación y una promoción objetiva de los estudiantes, proporcionar ambientes de prevención de desajustes en la comunidad educativa, fomentar la realización de estudios investigativos en casos pertinentes y procurar siempre una mejor prestación del servicio. La acción del psicopedagogo, en cambio, se dirige a lograr un buen proceso del aprendizaje mediante una dirección técnica de la enseñanza, contribuir al desarrollo de la educación a través de la experimentación de nuevos métodos existentes, conseguir participación en las actividades del servicio educativo mediante el trabajo en equipo y, establecer amplitud en la prestación de servicios educativos especiales, según los diversos tipos de educandos, y de educandos con limitaciones en el aprendizaje (Abisambra y Jiménez, 1973).

Desde la perspectiva de Peña y Acevedo (2011) la orientación es una acción desarrollada por la psicopedagogía:

En general, el psicopedagogo desempeña funciones ligadas a la formación personal de los estudiantes, trabajo con padres, en cátedras y proyectos referentes a educación de la sexualidad, apoyos académicos, formación docente, manejo de la convivencia, tratamiento de los problemas de aprendizaje, orientación vocacional, formación pedagógica en escuelas normales, currículo, investigación, acompañamiento de procesos educativos, gestión, trabajo con casos especiales, trabajo comunitario y coordinación; englobando, trabaja la orientación, problemas de aprendizaje y comunitarios. (p. 130)

En Colombia, la orientación educativa aparece ligada a servicio (el Decreto 1860 de 1994 en su artículo 40 hace referencia a servicio de orientación y reglamenta el artículo 92 de la Ley 115 de 1994, el cual habla desde la educación y está dirigido a implementar acciones pedagógicas - no acciones de orientaciónen torno a las actividades que desarrolla el mencionado servicio), ${ }^{3}$ actividad, línea de trabajo, acción,

3 Artículo 40. Servicio de orientación. En todos los establecimientos educativos se prestará un servicio de orientación estudiantil que tendrá como objetivo general el de contribuir al pleno desarrollo de la personalidad de los educandos, en particular en cuanto a: a) La toma de decisiones personales; b) la identificación de aptitudes e intereses; c) La solución de conflictos y problemas individuales, familiares y grupales; d) La participación en la vida académica, social y comunitaria; e) El desarrollo práctica, labor, herramienta y función ${ }^{4}$ (el Decreto 1278 del 2002 incluye el servicio de orientación estudiantil entre las actividades docentes, destaca que todas las actividades mencionadas por el artículo son desarrolladas por el genérico educador) entre otras; algunos la consideran ciencia o disciplina - se pensó que las aptitudes, intereses, necesidades y actitudes individuales podían medirse con parámetros científicos-y otros, profesión; de hecho, llama la atención - o debería llamarla - que un objeto sea concebido de formas tan diversas.

La orientación educativa no aparece clara en los planes de estudio de las carreras de psicología y psicopedagogía. En el caso específico de la psicopedagogía, en la Universidad Pedagógica y Tecnológica de Colombia, el plan de estudios de 1984 (UPTC, 1984) plantea actividades que han estado históricamente asociadas a la psicopedagogía, como lo son evaluación del rendimiento académico, planeación y ejecución de los programas escolares en sus diferentes niveles, realización de cursos de capacitación y perfeccionamiento docente, y capacitación a directoras de jardines infantiles y jardineras, entre otras; en investigación, analiza la problemática del desarrollo curricular, deserción escolar, rendimiento académico, métodos de estudio, técnicas didácticas y problemas de aprendizaje; el área de extensión se liga a la dirección de programas dirigidos a la comunidad.

En el de 1990 (UPTC, 1990), se plantean las mismas cuatro áreas de trabajo, con conceptualizaciones diferentes: la docencia se dirige a descubrir las diferencias individuales, a comprender la naturaleza de los procesos de enseñanza-aprendizaje y la filosofía y política de la educación colombiana, a identificar los

de valores, y f) Las demás relativas a la formación personal de que trata el artículo 92 de la Ley 115 de 1994.

4 Artículo 4. Función docente. La función docente es aquella de carácter profesional que implica la realización directa de los procesos sistemáticos de enseñanza-aprendizaje, lo cual incluye el diagnóstico, la planificación, la ejecución y la evaluación de los mismos procesos y sus resultados, y de otras actividades educativas dentro del marco del proyecto educativo institucional de los establecimientos educativos.

La función docente, además de la asignación académica, comprende también las actividades curriculares no lectivas, el servicio de orientación estudiantil, la atención a la comunidad, en especial de los padres de familia de los educandos; las actividades de actualización y perfeccionamiento pedagógico; las actividades de planeación y evaluación institucional; otras actividades formativas, culturales y deportivas, contempladas en el proyecto educativo institucional; y las actividades de dirección, planeación, coordinación, evaluación, administración y programación relacionadas directamente con el proceso educativo.

Las personas que ejercen la función docente se denominan genéricamente educadores, y son docentes y directivos docentes. 
modelos pedagógicos, y aportar a la construcción de una epistemología de la pedagogía y a la reconstrucción del saber pedagógico. En investigación, la idea es comprender los hechos y fenómenos de la realidad del proceso educativo y apropiarse de los principios básicos que rigen la investigación científica, la IAP y la etnografía. El área de asesoría está dirigida a identificar y aplicar la pedagogía propia de cada disciplina de saber. El área de extensión busca comprender y valorar la propia cultura, así como participar en la configuración de una identidad nacional.

En 1998 (UPTC, 2000), el programa adopta el concepto de competencias específicas y le asigna el énfasis de asesoría educativa, para ello, se mencionan funciones tales como: participar en la construcción de saber social, científico, tecnológico y pedagógico propio de su formación profesional, tomar decisiones, adquirir criterios, trabajar en equipo, y administrar de modo eficiente el tiempo libre. Así, las funciones están dirigidas a atención directa de estudiantes, ser miembro del equipo interdisciplinario y gestor de procesos de transformación e innovación. El profesional es concebido para desempeñarse en esencia como consultor pedagógico y diseñador de adaptaciones curriculares.

En la Universidad Pedagógica Nacional, el programa curricular de 1978 (UPN, 1978) está dirigido al rendimiento académico (asesor de docentes en la construcción de instrumentos de medición; participación en el establecimiento de la normalidad del rendimiento académico y en los factores que explican los rendimientos alcanzados), integración social (asesora y entrena a los profesores en la formación y conducción de grupos y equipos de trabajo; organiza sesiones de análisis de casos de comportamiento social; promueve y dirige convivencias), y promover satisfacción y éxito (diseñar, coordinar y ejecutar programas encaminados a obtener información sobre técnicas de solución de problemas y adopción de alternativas de decisión; diseñar, coordinar y participar en la ejecución de programas de exploración vocacional-educacional).

El programa de 1986 (UPN, 1986) está dirigido por la categoría de identidad profesional del maestro; en este sentido, trabaja por el desarrollo de la autonomía e identidad profesional, gestión y liderazgo de proyectos educativos, desarrollo de proyectos de investigación que generen alternativas de innovación pedagógica y organización de procesos de desarrollo cultural y educativo. El programa de 1998 (UPN, 2000) está orientado hacia dos énfasis: el de problemas de aprendizaje (identificación de problemas de aprendizaje, desarrollo de competencias de intervención preventiva y atención psicopedagógica, estrategias de abordaje investigativo) y el de orienta- ción y asesoría educativa (apoyo a los aprendizajes, desarrollo de la vocacionalidad, desarrollo socioafectivo). Esta versión recoge de nuevo la idea que ha rondado a la psicopedagogía durante varias décadas: que es el psicopedagogo el experto en problemas de aprendizaje y orientación escolar y educativa.

\section{¿Cierre?}

La educación se conceptualiza de diferente manera de acuerdo con las sociedades y épocas específicas, sin embargo, como común denominador se ha dirigido a procesos de humanización, formación de las nuevas generaciones y acople con la sociedad del momento, entre otras. La orientación fue creada como parte de este andamiaje, dirigida a los procesos de elección vocacional y carrera como complemento a lo que en su momento hacían las escuelas y pensando en la articulación del conjunto educativo, esto es, el paso de un nivel a otro y las exigencias del desarrollo económico, sintetizadas en la orientación profesional. En ese sentido 1) era innecesario crear una disciplina o profesión ligada a la orientación educativa, en cuanto esta última deriva sus saberes y prácticas de campos mucho más amplios y abarcadores; 2) ante la indefinición de la orientación, su trabajo en la escuela y en la educación varía de modo considerable en las instituciones y de acuerdo con los profesionales que la realizan; 3 ) el trabajo de la orientación educativa depende más de las necesidades a corto plazo de las instituciones que de un trabajo proyectivo; es lo eficaz y eficiente, el aquí y el ahora lo que direcciona su acción; 4) en Colombia, la orientación abandonó el ideal fundacional de elección de carrera y vocacionalidad, quedan unos pocos vestigios sin paradigmas ni dolientes; 5) los orientadores se agremiaron con prontitud lo cual les posibilitó voz en lo político, realizar eventos y tener lugar en los espacios donde se proyecta la acción, aun así, no lograron construir un conjunto.

La orientación educativa desde la perspectiva de sus fundadores - la educación y el desarrollo económico- resulta primordial. Hacer contrapeso a la competencia económica instaurada, inclusión de los jóvenes desde todas las perspectivas y necesidades, prevención y desarrollo humano, guía que permita al estudiante lograr autoconocimiento, y desarrollo de habilidades y adaptación a su comunidad son acciones que llevan a cabo los orientadores, pero no a través de saberes y conocimientos que ellos crean.

Por último, se requiere trabajar la orientación en torno al sujeto y a un desarrollo diferente. Orientar es una palabra vaga y ambigua que no hace mérito al trabajo desarrollado por los orientadores: 
La orientación educativa es un conjunto de procesos y procedimientos organizados sistemáticamente para ayudar a todos los estudiantes a desarrollar destrezas individuales y sociales en las áreas académicas, personal/social y de la carrera, a creer en sí mismo, usar y aplicar lo que se aprende, a fin de lograr la transición óptima de la institución educativa al trabajo, colaborar con los padres, docentes, docentesadministrativos y la comunidad, para promover el aprendizaje. (Mosquera, 2013, p. 4).

Al igual, es necesario un cambio de nombre impulsado por los propios orientadores. Una línea de trabajo encaminada en esta dirección da muchas posibilidades y resuelve muchas inquietudes.

\section{Referencias}

Abisambra, G. y Jiménez, C. (1973). Informe final de la prueba de interés para la selección de orientadores y psicopedagogos. Bogotá: Universidad Pedagógica Nacional.

Álvarez, M. y Bisquerra, R. (Coords.) (1996). Manual de orientación y tutoría. Barcelona: Práxis.

Augé. M. (2000). Los «no lugares» espacios del anonimato. Una antropología de la sobremodernidad. Barcelona: Gedisa.

Bourdieu, P. (1975). Campo intelectual y proyecto creador. En M. Barbut, P. Bourdieu, M. Godelier, A. Greimas, P. Macherey y J. Pouillon. Problemas del estructuralismo (pp. 135-182). México: Siglo XxI.

Bourdieu, P. (1990). Sociología y cultura. México: Grijalbo.

Bernstein, B. (1990). La construcción social del discurso pedagógico. Bogotá: Prodic-El Griot.

Best, F. (1988). Los avatares de la palabra pedagogía. Perspectivas, XVIII (2), 163-172.

Bisquerra, R. (1996). Orígenes y desarrollo de la orientación psicopedagógica. Madrid: Narcea.

Braunstein, N. (1982). ¿Cómo se constituye una ciencia? En N. Braunstein, M. Pasternac, G. Benedito y F. Saal, Psicología: Ideología y Ciencia (pp. 7-20). México, D.F.: Siglo XXI.

Cabrera, M. y Platone, M. (2005). Consideraciones teóricas y metodológicas acerca de la orientación vocacional en Venezuela. Revista de Pedagogía, XXVI (77), 455-482.

Carvajal, G. (2005). Psicopedagogía un territorio entre la razón y la sinrazón. Ponencia presentada en el Seminario Nacional ¿Es posible la epistemología de la psicopedagogía? Bogotá: Universidad Pedagógica Nacional.
Canguilhem, G. (1998). ¿Qué es la psicología? Revista Colombiana de Psicología, 7, 7-14.

Di Doménico, C. y Vilanova, A. (2000). Orientación vocacional: origen, evolución y estado actual. Orientación y sociedad, 2, 47-58. Recuperado de http:// www.scielo.org.ar/scielo.php?script=sci_arttext\&pi$\mathrm{d}=$ S1851-88932000000100003 \&lng=es\&tlng=es

Frigerio, G. y Diker, B. (2008). (Comps.). Prólogo. En Educar: posiciones acerca de lo común (pp. 7-11). Buenos Aires: Del Estante.

Hernández, 0. (2018). Percepción social hacia la orientación escolar en docentes orientadores de Bogotá. Bogotá: Universidad Pedagógica Nacional. [Artículo en proceso de arbitraje].

Mora, J. (2004). La necesidad del cambio educativo para la sociedad del conocimiento. Revista Iberoamericana de Educación. Recuperado de https://rieoei.org/historico/ documentos/rie35a01.htm

Montealegre, R. (1994). Vygostki y la concepción del lenguaje. Serie Cuadernos de Trabajo, 8. Facultad de Ciencias Humanas. Bogotá: Universidad Nacional de Colombia.

Moreu, A. y Bisquerra, R. (2002). Los orígenes de la psicopedagogía: el concepto y el término. Revista de Orientación Profesional, 13 (1), 17-29.

Morril, W., Oetting, E. y Hurst, J. (1974). Las dimensiones de la función del orientador. Caracas: documento no publicado.

Mosquera, J. (2013). La verdadera historia de la orientación en Colombia. Ponencia presentada en el I Congreso Latinoamericano de Formadores(as) de Orientadores(as). Valencia.

Parsons, F. (1909). Chosing a vocation. Boston: Houghton Mifflin.

Peña, F. (2006). Identidad profesional: la problemática de la psicopedagogía. Pedagogía y Saberes, 25, 109-120.

Peña, F. (2013). Distribución social del capital escolar en Colombia. Perspectiva socioeducativa. Bogotá: Alejandría Libros.

Peña, F. y Acevedo, S. (2011). El campo de la psicopedagogía: Discusiones, procesos de formación, identidad y prácticas. Revista Brasileira de Orientação Profissional, 12 (1), 127-132.

Pérez, J. (1992). Psicología y psicoanálisis. Revista Colombiana de Psicología, 1, 54-58.

Pérez, M. (1998). La cultura escolar en la sociedad neoliberal. Madrid: Morata. 
Presidencia de la República. Decreto 1860 de 1994 por el cual se reglamenta parcialmente la Ley 115 de 1994, en los aspectos pedagógicos y organizativos generales. Bogotá: Imprenta Nacional.

Presidencia de la República. Decreto 1278 del 2002. Estatuto de profesionalización docente. Bogotá: Imprenta Nacional.

Ruiz, Y. (2010). Temas para la Educación. Revista digital para profesionales de la enseñanza. Recuperado de https://www.feandalucia.ccoo.es/docu/p5sd7587.pdf

Subirana, J. (2013). La orientación en Europa, un recorrido por la diversidad. Recuperado de https://iesaugustobriga.educarex.es/orienta/_archivosPDF/016-032\%20 La\%20orientación \%20 en \%2 0Europa,\%20un\%20 recorrido\%20por\%20la\%20diversidad.pdf

Universidad Pedagógica y Tecnológica de Colombia. (1984). Resumen del proyecto de reestructuración de la Licenciatura en Psicopedagogía. Tunja: UPTC.

Universidad Pedagógica y Tecnológica de Colombia. (1990). Propuesta de reestructuración curricular del programa de Licenciatura en Psicopedagogía. Tunja: UPTC.

Universidad Pedagógica y Tecnológica de Colombia. (2000). Reestructuración del Programa de Psicopedagogía con énfasis en Asesoría Educativa. Tunja: UPTC.
Universidad Pedagógica Nacional. (1978). Reestructuración del Programa de Psicopedagogía. Bogotá: UPN.

Universidad Pedagógica Nacional. (1986). Programa de Psicología y Pedagogía. Bogotá: UPN.

Universidad Pedagógica Nacional. (2000). Programa de Psicología y Pedagogía. Reestructuración como producto del Decreto 272 de 1998. Bogotá: UPN.

Universidad Católica de Argentina. Programa de psicopedagogía. Recuperado de psicopedagogia-licenciatura--ciclo-/ perfil-del-titulo

Universidad Nacional General San Martín de Buenos Aires. Recuperado de http://unsam.edu.ar/escuelas/ humanidades/3/humanidades/psicopedagogia2

Zambrano, A. (2007). La psicopedagogía: ¿ciencia, saber o discurso? Cuadernos de Psicopedagogía, 4, 119-126.

Zuluaga, O. y Echeverri, A. (2003). Campo intelectual de la educación y campo pedagógico. Posibilidades, complementos y diferencias. En O. Zuluaga, A. Echeverri, A. Martínez, H. Quiceno, J. Sáenz y A. Álvarez. Pedagogía y Epistemología (pp. 111-126). Bogotá: Magisterio Universidad Pedagógica Nacional. 